\title{
The Effect of a Zinc Interlayer on the Microstructure and Mechanical Properties of a Magnesium Alloy (AZ31)- Aluminum Alloy (6060) Joint Produced by Liquid-Solid Compound Casting
}

\author{
RENATA MOLA, ${ }^{1}$ TOMASZ BUCKI ${ }^{1,3},{ }^{1,3}$ and MONIKA GWOŹDZIK ${ }^{2}$ \\ 1.-Faculty of Mechatronics and Mechanical Engineering, Department of Metal Science and \\ Manufacturing Processes, Kielce University of Technology, al. Tysiąclecia Państwa Polskiego 7, \\ 25-314 Kielce, Poland. 2.-Faculty of Production Engineering and Materials Technology, Institute \\ of Materials Engineering, Czestochowa University of Technology, ul. J.H. Dąbrowskiego 69, \\ 42-201 Czestochowa, Poland. 3.—e-mail: tbucki@tu.kielce.pl
}

Bimetallic AZ31/6060 joints were produced by compound casting. The process involved pouring liquid magnesium alloy onto a solid aluminum alloy insert placed in a mold. Inserts with and without a zinc surface layer were used. For an insert with no $\mathrm{Zn}$ layer, the bonding zone was characterized by a nonhomogeneous microstructure. In the area adjacent to the AZ31, there was a eutectic $(\gamma$ and $\alpha(\mathrm{Mg}))$. In the area close to the 6060 alloy, two continuous layers of the $\gamma$ and $\beta$ phases were detected. When a 6060 insert with a $\mathrm{Zn}$ layer was used, the bonding zone was mainly composed of Mg-Al-Zn phases. The joint without a $\mathrm{Zn}$ interlayer had low shear strength (5.5-11.3 $\mathrm{MPa}$ ). The presence of the $\mathrm{Zn}$ interlayer caused a significant increase in the joint strength (39.8-46.6 MPa). The micro-indentation data suggest a less brittle fracture character of the bonding zone with a $\mathrm{Zn}$ layer.

\section{INTRODUCTION}

Lightweight alloys including magnesium and aluminum are widely used in the transportation sector. Their major advantage is that they offer a lower mass of a vehicle and, consequently, lower fuel consumption. Recent years have seen increasing interest in the use of $\mathrm{Mg}$ and $\mathrm{Al}$ alloys to produce bimetallic materials. Because of their unique properties, $\mathrm{Mg} / \mathrm{Al}$ light bimetals have many potential applications, including the automotive industry. $\mathrm{Mg} / \mathrm{Al}$ components can be fabricated using various methods: TIG welding, ${ }^{1}$ resistance spot welding, ${ }^{2}$ ultrasonic spot welding, ${ }^{3}$ diffusion bonding, ${ }^{4}$ hot rolling, ${ }^{5,6}$ extrusion, ${ }^{7,8}$ friction stir welding, ${ }^{9}$ explosive cladding, ${ }^{10}$ or compound casting. ${ }^{1-19}$ The major problem related to the fabrication of $\mathrm{Mg} / \mathrm{Al}$ bimetallic joints is the occurrence of hard and brittle $\mathrm{Mg}-\mathrm{Al}$ intermetallic phases in the bonding zone, because they affect the properties of the bimetal elements, i.e., reduce their strength. The mechanical properties of such joints are dependent on the thickness and structure of the bonding zone, which, on the other hand, depend on the fabrication method. For example, when the process temperature is lower than the eutectic temperature of the $\mathrm{Mg}-\mathrm{Al}$ system $\left(437^{\circ} \mathrm{C}\right)$, a continuous bonding zone is formed. The zone is composed of two layers of $\mathrm{Mg}-\mathrm{Al}$ intermetallic phases: an $\mathrm{Al}_{3} \mathrm{Mg}_{2}$ layer on the $\mathrm{Al}$ side and a $\mathrm{Mg}_{17} \mathrm{Al}_{12}$ layer on the $\mathrm{Mg}$ side. The bonding zone in an $\mathrm{Mg} / \mathrm{Al}$ bimetal fabricated at a temperature higher than $437^{\circ} \mathrm{C}$ has a non-homogenous structure; apart from the $\mathrm{Al}-\mathrm{Mg}$ intermetallic phases, a eutectic $\left(\mathrm{Mg}_{17} \mathrm{Al}_{12}\right.$ and a solid solution of $\mathrm{Al}$ in $\mathrm{Mg}$ ) can be seen. The literature data show that joints with a bonding zone characterized by thick continuous layers of $\mathrm{Mg}$-Al intermetallic phases have the lowest plasticity. The brittleness of such joints can be reduced by reducing the thickness of the bonding zone, which can be achieved by properly selecting the process parameters. Another promising approach is to introduce an additional element between the alloy joints to change the microstructure of the bonding zone; this may cause a reduction 
in or prevention of the formation of $\mathrm{Mg}-\mathrm{Al}$ intermetallic phases and, consequently, an improvement in the properties of the joint. Some researchers indicate a positive effect of a $\mathrm{Zn}$ interlayer on the properties of joints between the magnesium and aluminum alloys when these are fabricated using different welding methods. ${ }^{20-25}$ Investigations concerning $\mathrm{Mg} / \mathrm{Al}$ joints fabricated in solid- or nonsolid-state joining processes include the analysis of the influence of other interlayers, such as nickel, ${ }^{25-27}$ cerium, ${ }^{28}$ titanium, ${ }^{29}$ tin, ${ }^{30}$ silver, ${ }^{31}$ copper, ${ }^{25,32}$ zinc-coated steel, ${ }^{25,33}$ tin-coated steel, ${ }^{25}$ and gold-coated steel, ${ }^{25}$ on the joint properties.

Liquid-solid compound casting is a promising and economical method suitable to fabricate $\mathrm{Mg} / \mathrm{Al}$ bimetal parts that are intricate in shape. Generally, the process consists of pouring a liquid Mg-based material onto a solid Al-based insert placed in a mold. The two materials join as they set. During the joining process, the reactions at the interface lead to the formation of hard and brittle intermetallic $\mathrm{Mg}-\mathrm{Al}$ phases in the bonding zone. ${ }^{12-17}$ Attempts have been made to improve the properties of joints fabricated using this method. The compound casting experiments by Papis et al. ${ }^{11}$ involved pouring melted $\mathrm{Mg}$ onto a surface-treated AlMg1 solid insert. The Mn surface layer produced by electrolytic deposition was several micrometers in thickness. It was shown that the additional Mn layer prevented the formation of low-melting hard $\mathrm{Mg}$-Al intermetallic phases at the interface of the Al-Mg couples. Jang et al. ${ }^{19}$ applied liquid-liquid compound casting to fabricate joints between $\mathrm{Mg}$ and $\mathrm{Al}$ alloys with a $\mathrm{Zn}$ interlayer. The process involved simultaneously pouring the $\mathrm{Mg}$ alloy on one side of a thin Zn barrier/plate placed in the mold and the $\mathrm{Al}$ alloy on the other. The presence of the $\mathrm{Zn}$ interlayer, however, did not cause an improvement in the mechanical properties of the joint.

In this study, AZ31 and 6060 alloys were joined by liquid-solid compound casting: 6060 aluminum alloy inserts with and without a Zn layer were used. The thin $\mathrm{Zn}$ layer was formed on the 6060 alloy insert by diffusion bonding. The aim of the experiments was to determine how the presence of the $\mathrm{Zn}$ layer affected the microstructure, composition and properties of the bonding zone. The microstructure of the bonding zone between the alloys was examined using light microscopy (LM) and scanning electron microscopy (SEM). The chemical composition was determined with an $\mathrm{x}$ ray energy dispersive spectrometer (EDS). X-ray diffraction (XRD) was applied to identify the phases present in the bonding zone. Finally, shear strength tests and microhardness measurements were carried out to analyze the effect that the additional $\mathrm{Zn}$ layer had on the properties of the joints.

\section{EXPERIMENTAL DETAILS}

Two light alloys, AZ31 Mg alloy and $6060 \mathrm{Al}$ alloy, were joined by liquid-solid compound casting. AZ31 with a composition (wt.\%) of $3.07 \mathrm{Al}, 1.05 \mathrm{Zn}, 0.31$
$\mathrm{Mn}$ and balance $\mathrm{Mg}$ was used as the casting material. The solid inserts placed in a mold were made of $6060 \mathrm{Al}$ alloy (Al-0.5Si-0.45Mg-0.19Mn). The 10-mm-thick samples were cut from a $30-\mathrm{mm}$ diameter rod. Two types of inserts, i.e., with or without a $\mathrm{Zn}$ surface layer, were analyzed. The thin $\mathrm{Zn}$ layer was formed on the $\mathrm{Al}$ alloy substrate by diffusion bonding. The 6060 alloy specimen in contact with the $0.1-\mathrm{mm} \mathrm{Zn}$ plate was annealed in a vacuum furnace at $375^{\circ} \mathrm{C}$ for 20 min under a pressure of $3 \mathrm{MPa}$, which ensured good bonding of the materials. The microstructure of the 6060 insert with a $\mathrm{Zn}$ layer is shown in Fig. 1. As can be seen, the $\mathrm{Al}$ alloy specimen and the $\mathrm{Zn}$ plate were successfully joined by diffusion bonding; the bonding zone formed as a result of interdiffusion had a thickness of about $10 \mu \mathrm{m}$. When the casting was performed for an insert without a $\mathrm{Zn}$ layer, the steel mold with the insert inside was preheated to $300^{\circ} \mathrm{C}$. The mold containing an insert with a $\mathrm{Zn}$ layer was preheated to $170^{\circ} \mathrm{C}$. The mold with a solid $\mathrm{Al}$ alloy insert was filled with AZ31 heated to a temperature of $660^{\circ} \mathrm{C}$ under pure argon atmosphere.

The specimens were prepared for microscopic observations following standard metallographic procedures. The final polishing was performed using a $0.05-\mu \mathrm{m}$ colloidal silica suspension. In the final polishing stage, the disk was rinsed with water to remove the rest of the polishing agent from the specimen surface. Specimen preparation for the microscopic analysis did not involve etching. The final polishing revealed the microstructural details of the bonding zone. Corrosion attack during polishing with water was rather slow for the intermetallic phases and very rapid for the solid solution. The microstructure of the bonding zone of the AZ31/ 6060 bimetal formed by the compound casting was determined by means of a Nikon ECLIPSE MA200 optical microscope and a JEOL JSM-5400 scanning electron microscope. Its chemical composition was established through EDS using an Oxford

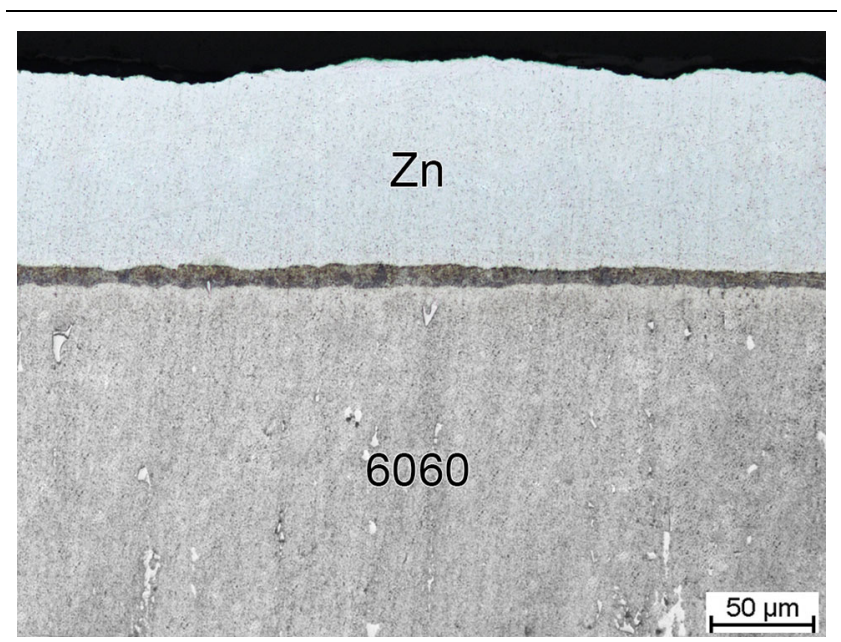

Fig. 1. LM image of a 6060 insert with a $\mathrm{Zn}$ layer formed by diffusion bonding. 
Instruments ISIS 300 analysis system. The phases were identified by applying a Seifert $3003 \mathrm{~T} / \mathrm{T}$ x-ray diffractometer with the radiation originating from a copper anode tube $\left(\lambda_{\mathrm{Cu}}=0.154 \mathrm{~nm}\right)$. The XRD measurements were performed using the following parameters: start angle $20^{\circ}$ and end angle $90^{\circ}$.

The strength of the AZ31/6060 bimetallic joints with and without a $\mathrm{Zn}$ interlayer was determined through a simple shear test. As pure shear is a stress state that is difficult to achieve, simple shear tests were carried out. In a simple shear test, large tangential stresses occur together with small normal stresses due to bending or tension. Simple shear is assumed to be a case of shear when a uniform shear stress state is observed in a crosssection, with bending stresses being negligible. A LabTest5.20SP1 universal testing machine with a displacement rate of $10 \mathrm{~mm} / \mathrm{min}$ was used. A nonstandard test was performed to measure the shear strength of the joints. Figure 2 shows a schematic diagram of the shear test setup and the specimen with dimensions. ${ }^{17,18}$ The tests were conducted for six specimens: three with and three without a $\mathrm{Zn}$ layer. The specimens were fixed in clamps tightened with screws, as shown in Fig. 2.

The microhardness of the joints was measured with a MATSUZAWA MMT Vickers hardness tester under a load of $100 \mathrm{~g}$.

\section{RESULTS AND DISCUSSION}

Figure 3a shows the bonding zone of an AZ31/ 6060 bimetal sample produced by pouring AZ31 melted to a temperature of $660^{\circ} \mathrm{C}$ onto a solid 6060 aluminum alloy insert preheated to $300^{\circ} \mathrm{C}$. As can be seen, the bonding zone forming between the alloys was continuous and its thickness reached about $400 \mu \mathrm{m}$. It had a non-homogeneous microstructure: a darker thinner region was observed on the AZ31 magnesium alloy side and

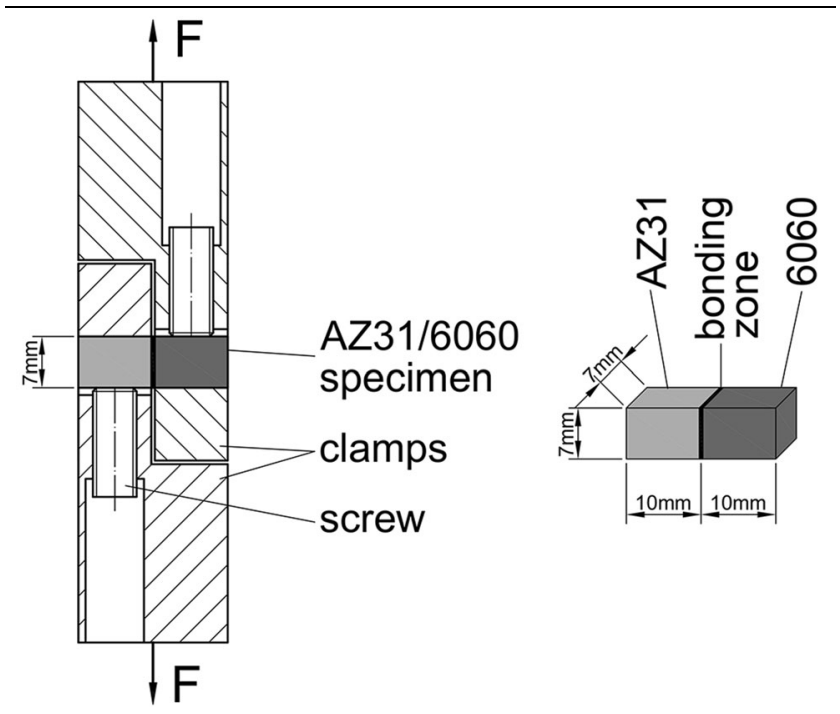

Fig. 2. Schematic diagram of the shear strength test. ${ }^{17,18}$ there was a lighter thicker region on the 6060 aluminum alloy side. The SEM images in Fig. 3b-d show details of the microstructure of the bonding zone. Table I provides the results of the quantitative EDS analysis for points 1-9 in Fig. $3 b-d$. The microstructure of the bonding zone was characterized on the basis of the EDS x-ray microanalysis results and the $\mathrm{Mg}$-Al phase diagram. ${ }^{34}$ At higher magnification, in the darker region of the bonding zone close to the AZ31 (Fig. 3b), a two-phase structure composed of light and dark phases can be distinguished. The quantitative EDS analysis revealed that the light phase (point 1) was the $\gamma$ $\left(\mathrm{Mg}_{17} \mathrm{Al}_{12}\right)$ intermetallic phase, while the dark phase (point 2) was a solid solution of $\mathrm{Al}$ in $\mathrm{Mg}$. This indicates that the two-phase structure was a eutectic containing $\gamma$ and a solid solution of $\mathrm{Al}$ in $\mathrm{Mg}$. A small amount of $\mathrm{Zn}$ was detected in the areas of the $\gamma$ intermetallic phase. It is commonly known that $\mathrm{Zn}$ can replace some of the $\mathrm{Al}$ atoms in the $\gamma$ intermetallic phase. ${ }^{35}$ In the eutectic closer to the lighter region of the bonding zone, there were light dendrites (point 3 in Fig. 3b and point 4 in Fig. 3c) with a composition similar to that of the $\gamma$ phase. Locally, regularly shaped dark particles (point 5 in Fig. 3c) were observed in the bonding zone. The particles had an $\mathrm{Mg}: \mathrm{Si}$ ratio of nearly $2: 1$, which corresponds to the stoichiometry of the $\mathrm{Mg}_{2} \mathrm{Si}$ phase. The quantitative EDS analysis in the lighter region below the eutectic (point 6 in Fig. 3c) also indicates the presence of the $\gamma$ phase. The regularly shaped dark particles of the $\mathrm{Mg}_{2} \mathrm{Si}$ phase (point 7 in Fig. 3d) were also observed in the lighter region of the bonding zone. The chemical composition of the lighter region close to the 6060 alloy (points 8 and 9 in Fig. 3d) corresponds to that of the $\beta$ (formula $\mathrm{Al}_{3} \mathrm{Mg}_{2}$ ) intermetallic phase. In the area adjacent to the AZ31 alloy, fine, white, needle-like particles of a multi-component phase rich in $\mathrm{Al}, \mathrm{Mn}$ and $\mathrm{Fe}$ can be observed locally. The fine, white, multi-component phase particles found close to the 6060 were rich in $\mathrm{Al}, \mathrm{Si}$ and Fe. Most probably, elements such as $\mathrm{Mn}$ and $\mathrm{Fe}$ originated from the commercially pure alloys used in this study; thus, white multicomponent phases rich in these elements are minor structural constituents of the bonding zone.

When a 6060 alloy insert with a thin $\mathrm{Zn}$ surface layer was used, the bonding zone had a different microstructure. Figure $4 \mathrm{a}$ illustrates the bonding zone of an AZ31/6060 bimetal sample fabricated by pouring the AZ31 alloy melted to a temperature of $660^{\circ} \mathrm{C}$ onto a solid 6060 alloy insert with a $\mathrm{Zn}$ surface layer preheated to $170^{\circ} \mathrm{C}$. The bonding zone that formed under such conditions was continuous but it was thicker (about $500 \mu \mathrm{m}$ ) than that obtained for an insert with no Zn layer present, despite the fact that the initial temperature of the insert was lower. In this case, the bonding zone also had a non-homogenous microstructure with a thicker darker region on the AZ31 alloy side and a thinner, lighter region on the 6060 alloy side. 

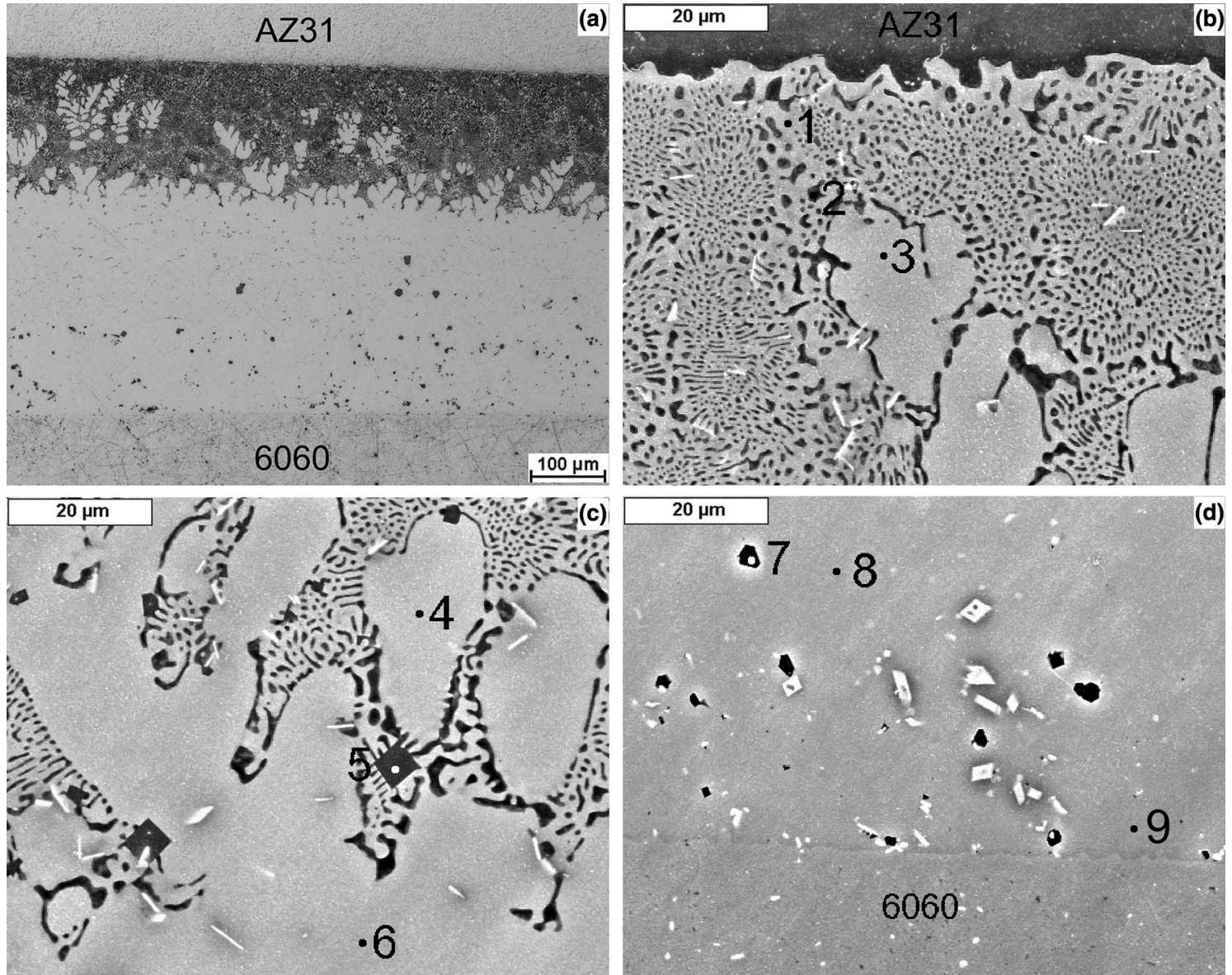

Fig. 3. Microstructure of the bonding zone of an AZ31/6060 bimetallic sample: (a) low-magnification LM image, (b-d) high-magnification SEM images.

Table I. EDS results corresponding to the points marked in Fig. 3b-d

\begin{tabular}{|c|c|c|c|c|}
\hline \multirow[b]{2}{*}{$\underline{\text { Point }}$} & \multicolumn{4}{|c|}{ at.\% } \\
\hline & Mg & Al & $\mathbf{Z n}$ & $\mathbf{S i}$ \\
\hline 1 & 65.98 & 33.79 & 0.23 & - \\
\hline 2 & 93.28 & 6.72 & - & - \\
\hline 3 & 63.96 & 35.86 & 0.18 & - \\
\hline 4 & 62.53 & 37.47 & - & - \\
\hline 5 & 67.36 & 0.16 & - & 32.48 \\
\hline 6 & 60.28 & 39.72 & - & - \\
\hline 7 & 66.47 & 0.79 & - & 32.74 \\
\hline 8 & 41.78 & 58.22 & - & - \\
\hline 9 & 40.98 & 59.02 & - & - \\
\hline
\end{tabular}

Figure $4 b-d$ shows the SEM images of the bonding zone with points of the quantitative analysis. Table II summarizes the EDS data. From Fig. 4b, it is clear that the darker region close to the AZ31 had a two-phase structure with light and dark phases (points 1 and 2, respectively). The gray phase areas (point 3 ) and the regularly shaped dark particles (point 4) co-occurred locally with the twophase structure. The chemical composition of the light phase was similar to that of the ternary $\varphi$ intermetallic phase (formula $\mathrm{Mg}_{6}(\mathrm{Al}, \mathrm{Zn})_{5}$ or $\mathrm{Mg}_{5} \mathrm{Al}_{2} \mathrm{Zn}_{2}$ ). The dark phase was a solid solution of $\mathrm{Al}$ and $\mathrm{Zn}$ in $\mathrm{Mg}$. These results suggest that the twophase structure was a eutectic composed of the $\varphi$ phase and a solid solution of $\mathrm{Al}$ and $\mathrm{Zn}$ in $\mathrm{Mg}$. The quantitative EDS analysis showed that the gray areas were the $\gamma-\mathrm{Mg}_{17} \mathrm{Al}_{12}$ intermetallic phase. The chemical composition of the dark particles corresponded to that of the $\mathrm{Mg}_{2} \mathrm{Si}$ phase. In the eutectic area close to the light region of the bonding zone (Fig. 4c), there were areas of the light phase (point 5). The contents of $\mathrm{Mg}, \mathrm{Al}$ and $\mathrm{Zn}$ in these areas were similar to those reported in the light region (point 6) below the eutectic structure. From the EDS results it is clear that the light areas and the light matrix were the $\tau$ (formula $\mathrm{Mg}_{32}(\mathrm{Al}, \mathrm{Zn})_{49}$ ) intermetallic phase. In the bonding zone close to the 6060 alloy, a two-phase structure is visible. The literature data indicate that the $\tau$ intermetallic phase extends over a wide range of values of the $\mathrm{Zn} / \mathrm{Al}$ ratio and the $\mathrm{Mg}$ content is known to vary by a few percent. $^{36,37}$ The quantitative analysis of the light region above the two-phase structure (point 7) revealed the presence of the $\tau$ phase. The composition of the light phase of the two-phase structure 

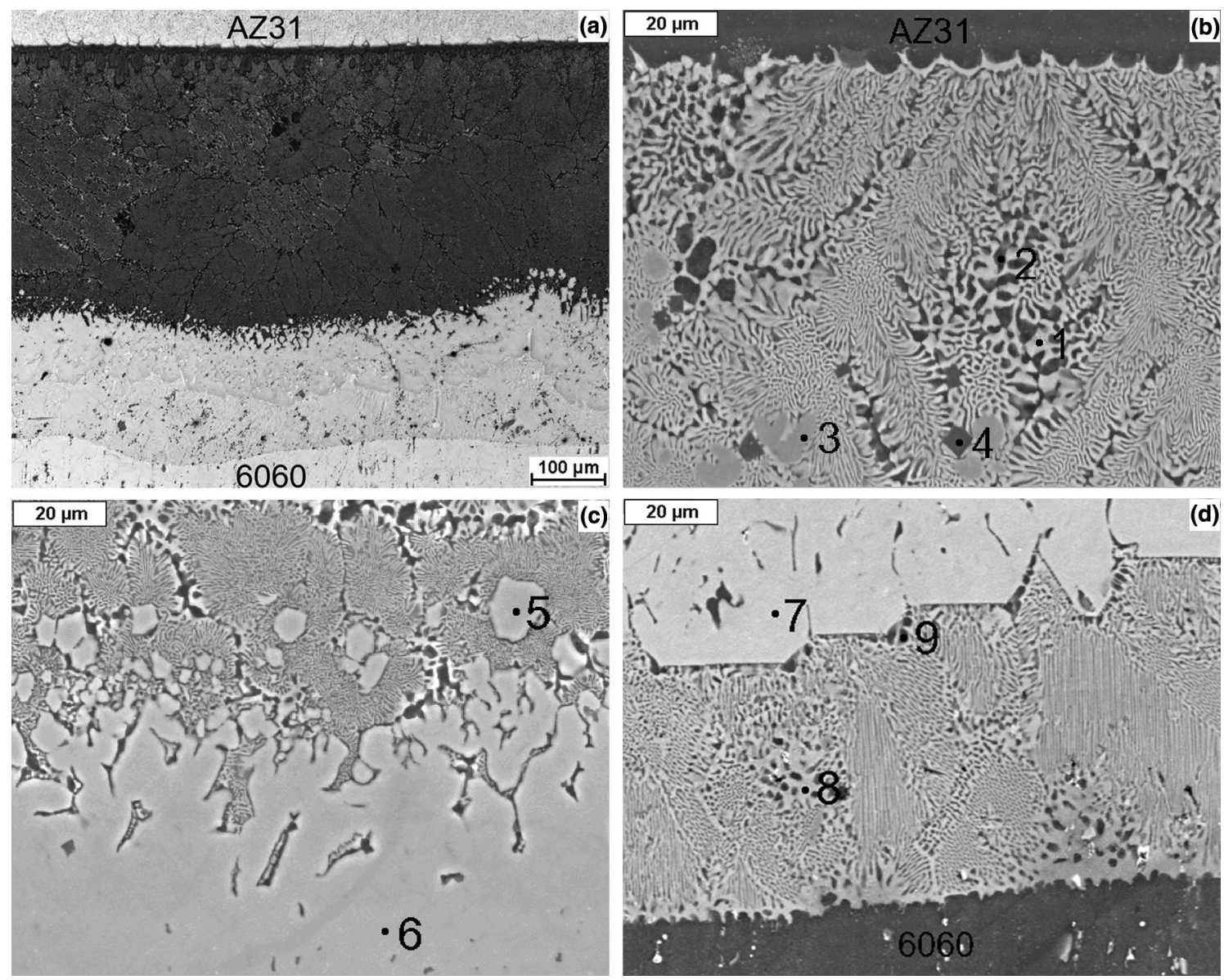

Fig. 4. Microstructure of the bonding zone of an AZ31/6060 bimetallic sample obtained from a 6060 insert with a Zn layer: (a) low-magnification LM image, (b-d) high-magnification SEM images.

Table II. EDS results corresponding to the points marked in Fig. 4b-d

\begin{tabular}{|c|c|c|c|c|}
\hline \multirow[b]{2}{*}{ Point } & \multicolumn{4}{|c|}{ at. $\%$} \\
\hline & Mg & Al & Zn & Si \\
\hline 1 & 59.39 & 17.56 & 23.05 & - \\
\hline 2 & 91.27 & 5.31 & 3.42 & - \\
\hline 3 & 60.18 & 29.96 & 9.86 & - \\
\hline 4 & 65.74 & 1.14 & - & 33.12 \\
\hline 5 & 42.35 & 29.05 & 28.60 & - \\
\hline 6 & 41.53 & 28.62 & 29.85 & - \\
\hline 7 & 35.63 & 34.94 & 29.43 & - \\
\hline 8 & 34.42 & 50.03 & 15.55 & - \\
\hline 9 & 5.89 & 90.64 & 3.47 & - \\
\hline
\end{tabular}

(point 8) also corresponded to that of the $\tau$ phase. The dark phase (point 9) was a solid solution of $\mathrm{Mg}$ and $\mathrm{Zn}$ in $\mathrm{Al}$. From these results, it is evident that the two-phase structure observed on the $\mathrm{Al}$ alloy side was a eutectic containing the $\tau$ intermetallic phase and a solid solution of $\mathrm{Mg}$ and $\mathrm{Zn}$ in $\mathrm{Al}$. Locally, fine, white particles of the multicomponent phases rich in $\mathrm{Fe}$ and/or $\mathrm{Mn}$ are also observed in the bonding zone.
The results of the XRD analysis provided in Fig. 5 coincide with the data obtained through the EDS analysis. For both types of bonding zone, the peaks identified were those of aluminum, magnesium and the following phases: $\mathrm{Mg}_{2} \mathrm{Si}, \gamma$ and traces of $\mathrm{Al}_{6}(\mathrm{Fe}, \mathrm{Mn})$ and $\mathrm{Al}_{5} \mathrm{FeSi}$. From the diffractograms, it is apparent that the $\mathrm{Mg}_{2} \mathrm{Si}$ phase occurred mainly in the bonding zone when an insert without a $\mathrm{Zn}$ layer was used. At an angle of $2 \theta$ corresponding to $40.11^{\circ}$, a peak of this phase (Fig. 5a) was observed. When the joint was produced from an insert without a $\mathrm{Zn}$ layer, the structure of the bonding zone also contained the $\beta$ phase. The bonding zone in the AZ31/6060 joint obtained for an $\mathrm{Al}$ insert with a $\mathrm{Zn}$ layer was characterized by the presence of the $\varphi$ and $\tau$ phases, as shown in Fig. 5b. Because of similar interplanar distances, the peaks of these phases were identified as common peaks.

The shear tests were carried out to assess the influence of the $\mathrm{Zn}$ interlayer on the properties of AZ31/6060 joints fabricated by liquid-solid compound casting. Figure 6 illustrates the shear stressdisplacement curves obtained from the shear tests. The shape of the shear curves plotted for both types of joint, i.e., without and with a $\mathrm{Zn}$ layer (Fig. 6a and $b$, respectively), is typical of brittle material. 

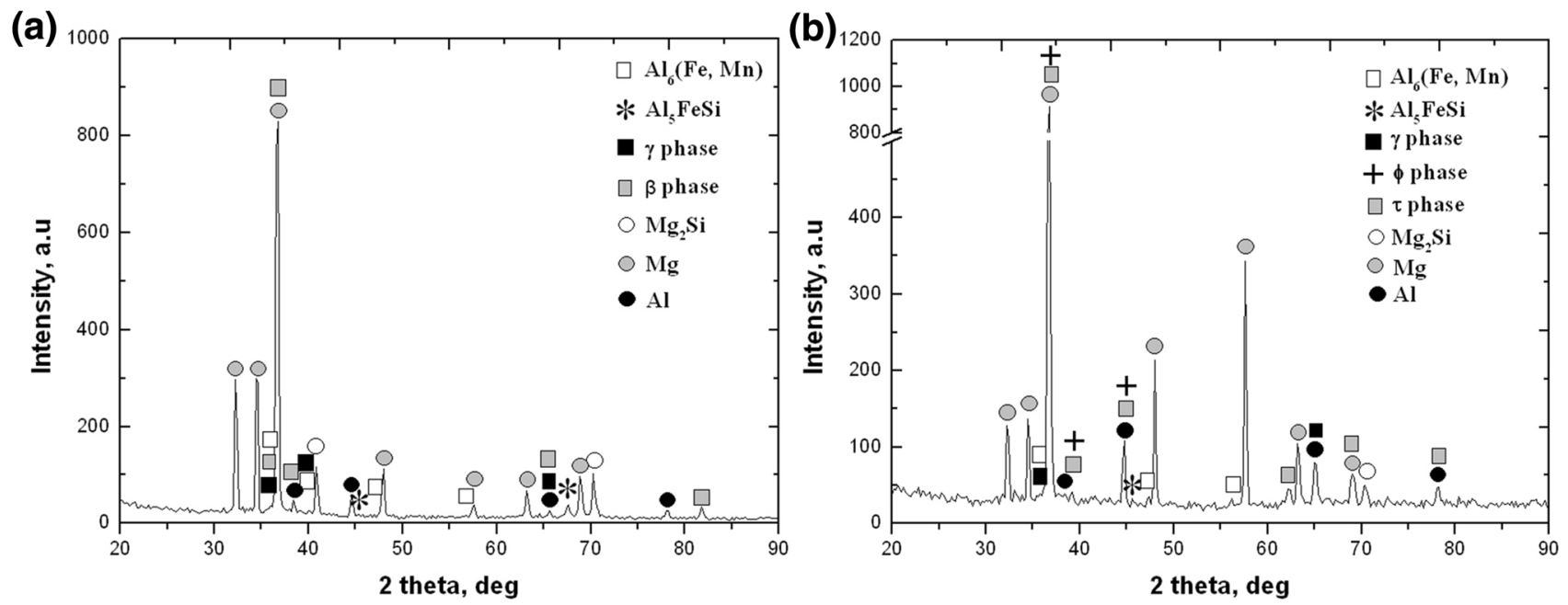

Fig. 5. X-ray diffraction spectra for the bonding zone of an AZ31/6060 bimetallic sample obtained from a 6060 insert: (a) without a Zn layer, (b) with a Zn layer.
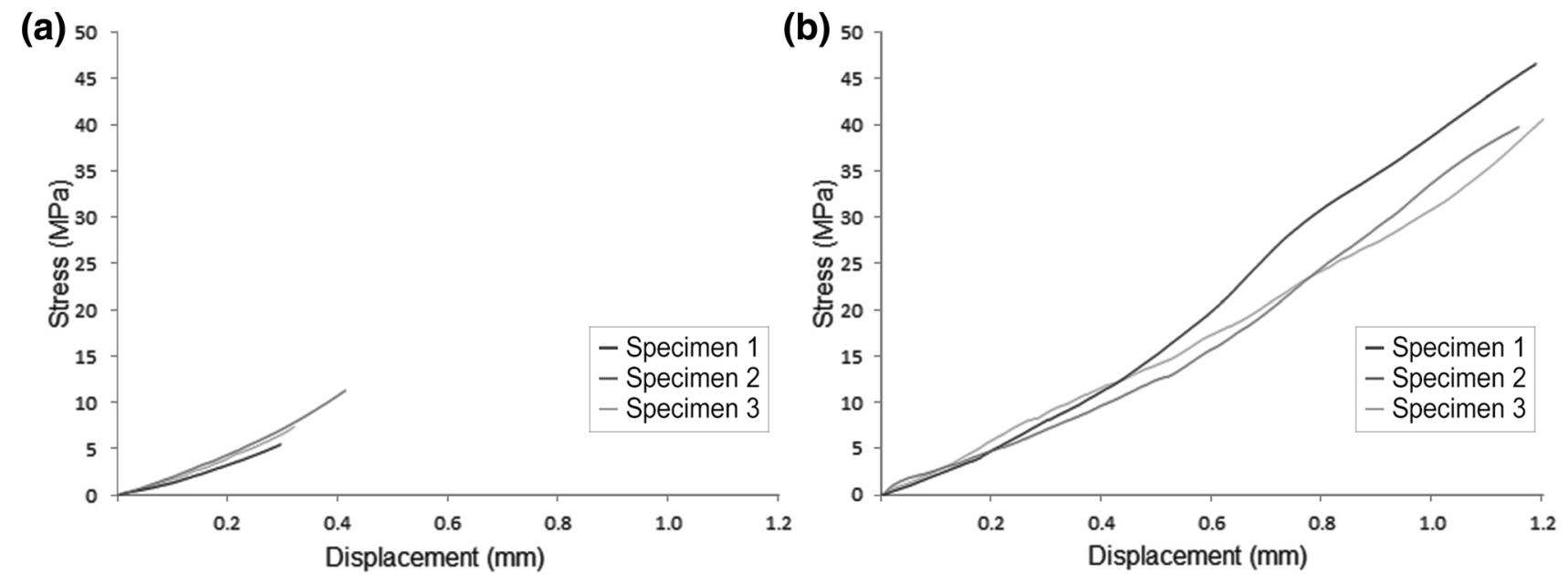

Fig. 6. The shear stress-displacement curves for the specimens: (a) without a Zn layer, (b) with a Zn layer.

The results showed that the AZ31/6060 joint without a $\mathrm{Zn}$ interlayer was characterized by low strength ranging from $5.5 \mathrm{MPa}$ to $11.3 \mathrm{MPa}$. The data obtained for the specimens with a $\mathrm{Zn}$ interlayer (39.8-46.6 MPa) indicated a significant effect of the Zn interlayer on the strength of the AZ31/6060 joint.

The results of the shear tests were in good agreement with the literature data; similar observations have been made for a $\mathrm{Zn}$ interlayer in joints between $\mathrm{Al}$ and $\mathrm{Mg}$ fabricated using various methods. ${ }^{20-24}$ For example, Liu et al. ${ }^{20}$ revealed that the use of a $\mathrm{Zn}$ filler metal had an effect on the microstructure and mechanical properties of AZ31/ 6061 GTAW joints. The tensile strength of bimetal $\mathrm{Mg} / \mathrm{Al}$ joints without a $\mathrm{Zn}$ filler metal reached around $28 \mathrm{MPa}$. Introducing a $\mathrm{Zn}$ filler metal resulted in higher joint strength $(93 \mathrm{MPa})$. Zhang and Song ${ }^{21}$ describe the joining of AZ31 magnesium alloy to 2B50 aluminum alloy by MIG welding. In their experiments, they used a Zn interlayer in the form of $\mathrm{Zn}$ foil placed between the joined alloys. When the two alloys were welded directly, i.e., with no layer inbetween, cracks occurred in the bonding zone. The use of the $\mathrm{Zn}$ foil in the welding process improved the quality of the joint and increased its tensile strength to $64 \mathrm{MPa}$. The influence of the $\mathrm{Zn}$ interlayer was also examined by Liu et al. in brazing to join AZ31 to $6061 .^{22,23} \mathrm{~A}$ Zn layer was fabricated on the surface of a 6061 aluminum alloy plate by hot-dipping it in a Zn-based alloy bath. The surfacetreated 6061 alloy was joined to AZ31 by reactive brazing performed in a traditional air furnace. The study involved determining the shear strength of the joints with and without a $\mathrm{Zn}$ interlayer. The presence of the $\mathrm{Zn}$ layer caused a significant improvement in the shear strength of the joint; the number of defects in the bonding zone was also lower. A positive effect of a $\mathrm{Zn}$ interlayer on the joint properties was also noticed for AZ31/6061 joints fabricated by diffusion bonding. ${ }^{24}$ The shear 
strength of joints without a $\mathrm{Zn}$ layer was up to $41.3 \mathrm{MPa}$. However, when an $\mathrm{Zn}$ interlayer was applied, the joint had much higher strength, i.e. 75$83 \mathrm{MPa}$. The effect of a $\mathrm{Zn}$ interlayer was also examined for $\mathrm{Mg} / \mathrm{Al}$ bimetal joints produced by liquid-liquid compound casting. ${ }^{19}$ AZ91D magnesium alloy and A356 aluminum alloy were simultaneously poured on each side of a $\mathrm{Zn}$ thin foil placed in a mold. It should be noted, however, that there was no improvement in the mechanical properties of the joint. The shear strength of the joint was around $10.91 \mathrm{MPa}$ and the fracture was brittle in nature.

Figures 7 and 8 show indentations left by the Vickers indenter in the AZ31/6060 joints without and with a Zn layer, respectively. The values of the microhardness measurements are provided next to the indentations. From these results, it is clear that, in both cases, the bonding zone had much higher microhardness than the joined alloys, and the microhardness varied across the bonding zone. In the case of joints with no Zn interlayer (Fig. 7), there was an irregular transition between the $\gamma$ phase layer and the $\beta$ phase layer in the lighter region of the bonding zone. The highest hardness was reported in the $\beta$ phase layer (216.6-230.0 HV0.1) close to the 6060 aluminium alloy. Slightly lower values of microhardness were observed in the $\gamma$ phase layer close to the eutectic (197.7-204.9 HV0.1). The microhardness of the eutectic close to the AZ31 magnesium alloy, which contained the $\gamma$ phase and a solid solution of $\mathrm{Al}$ in $\mathrm{Mg}$, ranged from 180.6 HV0.1 to 182.4 HV0.1. The fracture behavior of the bonding zone was analyzed on the basis of the micro-indentation data. The higher magnification images in Fig. 7b, $c$ and d show indentations left in the characteristic areas of the bonding zone: the eutectic, the $\gamma$ phase and the $\beta$ phase, respectively. In brittle materials, cracking generally occurs during the indenter loading. From Fig. 7b, it is evident that no cracks were observed around of the indentation left in the eutectic. In the $\beta$ and $\gamma$ phase areas, there were long radial cracks propagating from the corners of the indentations, as shown in Fig. 7c and $\mathrm{d}$, respectively. Such crack propagation is characteristic of brittle materials. The analysis of the bonding zone of the AZ31/6060 joint fabricated with a Zn layer (Fig. 8a) shows that the lowest values of microhardness (159.1-167.6 HV0.1) were obtained in the thick darker region with a eutectic structure ( $\varphi$ intermetallic phase and a solid solution of $\mathrm{Al}$ and $\mathrm{Zn}$ in $\mathrm{Mg}$ ) located close to the $\mathrm{Mg}$ alloy. No cracks were observed around the indentation (Fig. 8b). The highest hardness values were reported for the $\tau$ phase region (209.8-214.3 HV0.1) below the eutectic

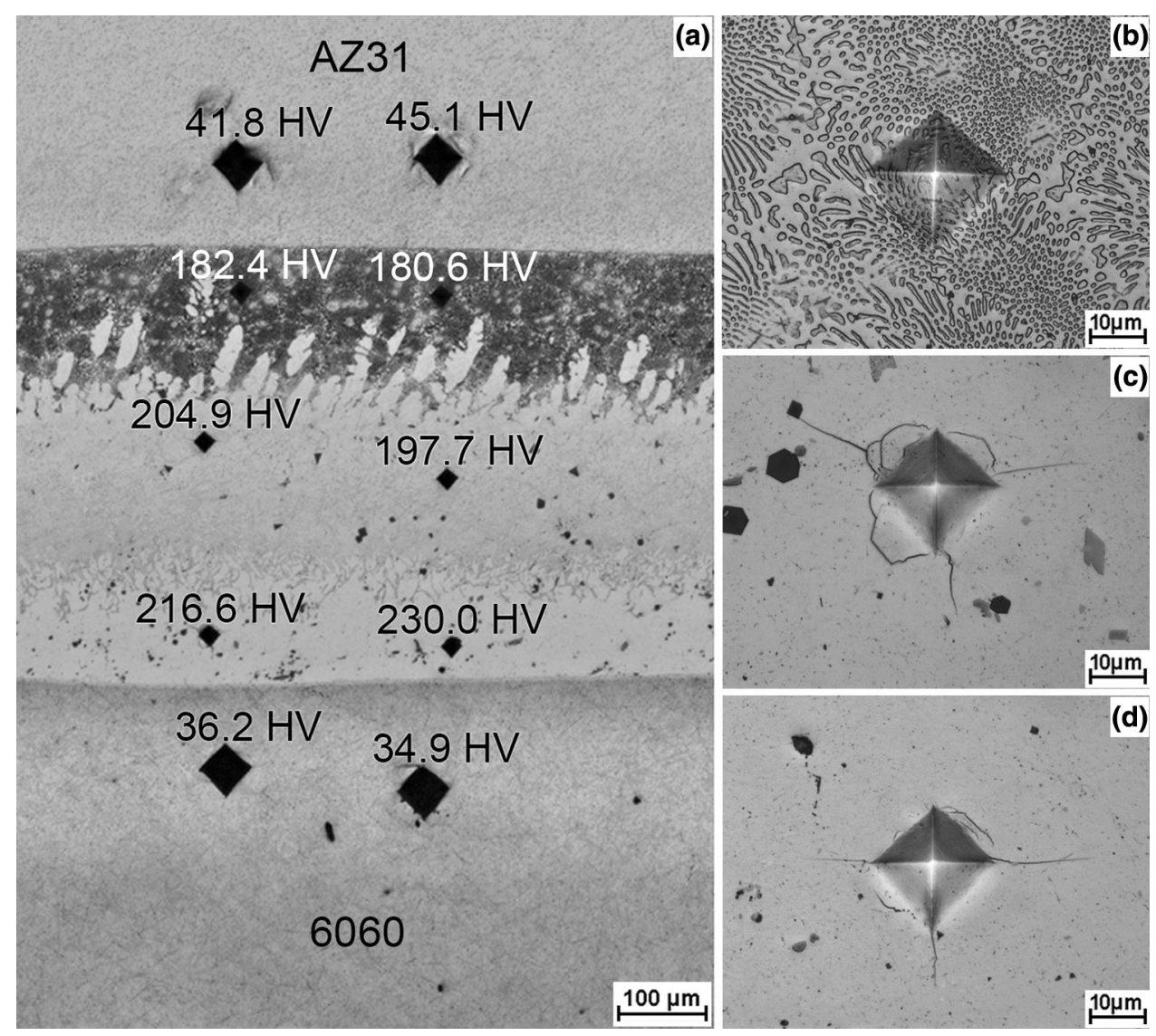

Fig. 7. Indentations left after the Vickers tests for the bonding zone without a $\mathrm{Zn}$ layer (a). Higher-magnification images showing the indentations in: the eutectic close to the AZ31 alloy (b), the $\gamma$ phase (c) and the $\beta$ phase (d). 


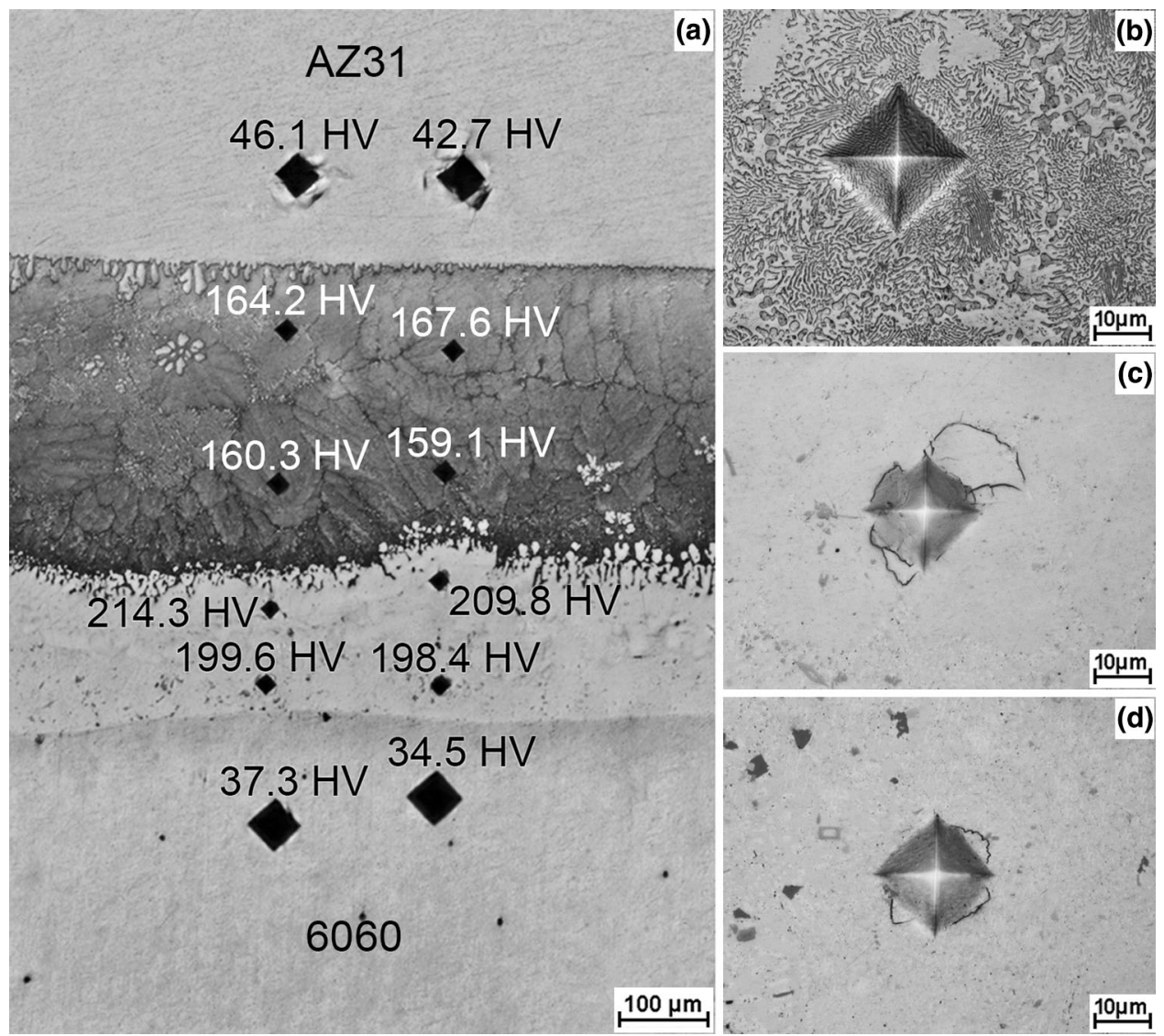

Fig. 8. Indentations left after the Vickers tests for the bonding zone with a Zn layer (a). Higher-magnification images showing the indentations in: the eutectic close to the AZ31 alloy (b), the $\tau$ phase (c) and the eutectic close to the 6060 alloy (d).

structure. As can be seen from Fig. 8c, there were no long radial cracks propagating from the indentation corners. Cracking was observed around the indentation, which indicates a less brittle fracture character of this intermetallic phase than that of the $\beta$ or $\gamma$ phases. Lower values of microhardness were reported in the two-phase region (eutectic containing the $\tau$ intermetallic phase and a solid solution of $\mathrm{Mg}$ and $\mathrm{Zn}$ in $\mathrm{Al}$ ) close to the $\mathrm{Al}$ alloy (198.4-199.6 HV0.1). Single cracks were present along the indentation edges (Fig. 8d).

To summarize, the experimental results presented in this article suggest that the improvement in the mechanical properties of the AZ31/6060 joints was a consequence of the modification of the bonding zone microstructure through the application of a $\mathrm{Zn}$ interlayer. In the case of joints fabricated without a $\mathrm{Zn}$ interlayer, the microstructure of the bonding zone was characterized by continuous, thick layers of the $\gamma$ and $\beta$ binary $\mathrm{Mg}-\mathrm{Al}$ phases on the 6060 alloy side. It is commonly known that both $\mathrm{Mg}-\mathrm{Al}$ phases exhibit high brittleness. ${ }^{12}$ The microindentation data presented above also imply the brittle nature of the $\mathrm{Mg}-\mathrm{Al}$ intermetallic phases. Thus, it is extremely important to reduce the formation of continuous layers of these phases in the bonding zone in order to improve the strength of the joint. The use of a $\mathrm{Zn}$ interlayer resulted in a significant modification of the joint microstructure. The bonding zone on the 6060 alloy side was mainly composed of a eutectic and irregular areas of the $\tau$ $\mathrm{Mg}-\mathrm{Al}-\mathrm{Zn}$ ternary intermetallic phase. Such a microstructure had a positive effect on the joint strength: a less brittle character of the bonding zone was observed than in the case of continuous layers of the $\gamma$ and $\beta$ phases.

\section{CONCLUSION}

This article has dealt with bimetallic AZ31/6060 joints produced by liquid-solid compound casting. The casting process involved pouring AZ31 magnesium alloy heated to $660^{\circ} \mathrm{C}$ onto a 6060 aluminum alloy insert placed in a steel mold. The $\mathrm{Al}$ alloy inserts were with or without a $\mathrm{Zn}$ surface layer. A thin $\mathrm{Zn}$ layer $(0.1 \mathrm{~mm})$ was formed on the 6060 alloy substrate by diffusion bonding. When an $\mathrm{Al}$ alloy insert without a $\mathrm{Zn}$ layer was used, the mold and the insert were preheated to $300^{\circ} \mathrm{C}$. The mold containing an insert with a $\mathrm{Zn}$ layer was preheated to $170^{\circ} \mathrm{C}$. Whichever the case, a continuous bonding zone formed between the alloys. Its thickness and microstructure were dependent on the parameters of the casting process. The bonding zone obtained 
for an $\mathrm{Al}$ alloy insert without a $\mathrm{Zn}$ layer was about $400 \mu \mathrm{m}$ in thickness and it had a non-homogeneous microstructure. In the area close to the AZ31 alloy, a eutectic structure ( $\gamma$ intermetallic phase and a solid solution of $\mathrm{Al}$ in $\mathrm{Mg}$ ) with some $\mathrm{Mg}_{2} \mathrm{Si}$ phase particles was observed. In the area adjacent to the 6060 alloy, there was a light region composed of two continuous layers of the $\gamma$ and $\beta$ intermetallic phases. The particles of the $\mathrm{Mg}_{2} \mathrm{Si}$ phase were locally distributed over the bonding zone. When a 6060 alloy insert with a $\mathrm{Zn}$ surface layer was used to produce a bimetallic joint, significant microstructural changes were reported. The bonding zone was composed primarily of $\mathrm{Mg}-\mathrm{Al}-\mathrm{Zn}$ phases: $\varphi$ intermetallic phase, a solid solution of $\mathrm{Al}$ and $\mathrm{Zn}$ in $\mathrm{Mg}, \tau$ intermetallic phase, and a solid solution of $\mathrm{Mg}$ and $\mathrm{Zn}$ in $\mathrm{Al}$. Although the initial temperature of the inserts was lower, the resulting bonding zone was thicker $(500 \mu \mathrm{m})$. The shear strength of the joint without a $\mathrm{Zn}$ interlayer ranged from $5.5 \mathrm{MPa}$ to 11.3 MPa. A much higher strength, varying from $39.8 \mathrm{MPa}$ to $46.6 \mathrm{MPa}$, was reported for the joint fabricated with a $\mathrm{Zn}$ interlayer. The microhardness tests show that both bonding zones exhibit much higher hardness than the materials joined. The higher shear strength values of the bonding zone with a $\mathrm{Zn}$ interlayer result from the lower brittleness of the bonding zone, as confirmed in the microindentation analysis. The experimental data show that the presence of a $\mathrm{Zn}$ prevented the formation of brittle $\mathrm{Mg}-\mathrm{Al}$ intermetallic phases and improved the properties of the joint.

\section{OPEN ACCESS}

This article is distributed under the terms of the Creative Commons Attribution 4.0 International License (http://creativecommons.org/licenses/by/4.0/ ), which permits unrestricted use, distribution, and reproduction in any medium, provided you give appropriate credit to the original author(s) and the source, provide a link to the Creative Commons license, and indicate if changes were made.

\section{REFERENCES}

1. P. Liu, Y.J. Li, H.R. Geng, and J. Wang, Mater. Lett. 61, 1288 (2007).

2. F. Hayat, Mater. Des. 32, 2476 (2011).

3. A. Panteli, Y.C. Chen, D. Strong, X. Zhang, and P.B. Prangnell, JOM 64, 414 (2012).

4. G. Mahendran, V. Balasubramanian, and T. Senthilvelan, Mater. Des. 30, 1240 (2009).
5. X.P. Zhang, T.H. Yang, S. Castagne, and J.T. Wang, Mater. Sci. Eng. A 528, 1954 (2011).

6. A. Wierzba, S. Mróz, P. Szota, A. Stefanik, and R. Mola, Arch. Metall. Mater. 60, 2821 (2015).

7. O. Golovko, S.M. Bieliaiev, F. Nürnberger, and V.M. Danchenko, Forsch. Ingenieurwes 79, 17 (2015).

8. L. Xiao and N. Wang, J. Nucl. Mater. 456, 389 (2015).

9. Y.S. Sato, S.H.C. Park, M. Michiuchi, and H. Kokawa, Scr. Mater. 50, 1233 (2004).

10. S. Mróz, G. Stradomski, H. Dyja, and A. Galka, ACME 15, 317 (2015).

11. K.J.M. Papis, J.F. Loffler, and P.J. Uggowitzer, Sci. China Ser. E 52, 46 (2009).

12. E. Hajjari, M. Divandari, S.H. Razavi, S.M. Emami, T. Homma, and S. Kamado, J. Mater. Sci. 46, 6491 (2011).

13. J. Sun, X. Song, T. Wang, Y. Yu, M. Sun, Z. Cao, and T. Li, Mater. Lett. 67, 21 (2012)

14. G. Li, W. Jiang, Z. Fan, Z. Jiang, X. Liu, and F. Liu, Int. J. Adv. Manuf. Technol. 91, 1355 (2017).

15. R. Mola, T. Bucki, and A. Dziadoń, I.O.P. Conf. Ser. Mater. Sci. Eng. 179, 1 (2017).

16. R. Mola, T. Bucki, and A. Dziadoń, Arch. Foundry Eng. 17, 202 (2017).

17. R. Mola and T. Bucki, Arch. Foundry Eng. 18, 71 (2018).

18. R. Mola and T. Bucki, Arch. Foundry Eng. 18, 203 (2018).

19. Z. Jiang, Z. Fan, W. Jiang, G. Li, Y. Wu, F. Guan, and H. Jiang, J. Mater. Process. Technol. 261, 149 (2018).

20. F. Liu, Z.D. Zhang, and L.M. Liu, Mater. Charact. 69, 84 (2012).

21. H.T. Zhang and J.Q. Song, Mater. Lett. 65, 3292 (2011).

22. L.M. Liu, J.H. Tan, and X.J. Liu, Mater. Lett. 61, 2373 (2007).

23. L.M. Liu, J.H. Tan, L.M. Zhao, and X.J. Liu, Mater. Charact. 59,479 (2008).

24. L.M. Zhao and Z.D. Zhang, Scr. Mater. 58, 283 (2008).

25. P. Penner, Resistance Spot Welding of Al to Mg with Different Interlayers (Waterloo: University of Waterloo, 2013), pp. $23-83$.

26. W. Chang, S. Rajesh, C. Chun, and H. Kim, J. Mater. Sci. Technol. 27, 199 (2011).

27. P. Penner, L. Liu, A. Gerlich, and Y. Zhou, Sci. Technol. Weld. Joint. 18, 541 (2013).

28. L. Liu, X. Liu, and S. Liu, Scr. Mater. 55, 383 (2006).

29. M. Gao, S. Mei, X. Li, and X. Zeng, Scr. Mater. 67, 193 (2012).

30. V. Patel, S. Bhole, and D. Chen, Sci. Technol. Weld. Joint. 17, 342 (2012).

31. Y. Wang, G. Luo, J. Zhang, Q. Shen, and L. Zhang, Mater. Sci. Eng. A 559, 868 (2013).

32. J. Shang, K. Wang, Q. Zhou, D. Zhang, J. Huang, and G. Li, Mater. Des. 34, 559 (2012).

33. P. Penner, L. Liu, A. Gerlich, and Y. Zhou, Weld. J. 93, 225 (2014).

34. B. Predel, Al-Mg (Aluminum-Magnesium), Landolt-Börnstein-Group IV Physical Chemistry, ed. O. Madelung (Springer, Berlin, 1991).

35. F. Czerwinski, Acta Mater. 53, 1973 (2005).

36. D.A. Petrov, Ternary Alloys, Vol. 7 (Weinheim: VCH, 1993).

37. V. Raghavan, J. Phase Equilibria Diffus. 28, 203 (2007).

Publisher's Note Springer Nature remains neutral with regard to jurisdictional claims in published maps and institutional affiliations. 